\title{
Use of Recycled Aggregates Made from Construction and Demolition Waste in Sustainable Road Base Layers
}

\author{
Evelio Teijón-López-Zuazo ${ }^{1, *(D)}$, Ángel Vega-Zamanillo ${ }^{2}$, Miguel Ángel Calzada-Pérez ${ }^{2}$ and \\ Ángel Robles-Miguel ${ }^{1}$ \\ 1 Department of Construction and Agronomy, Zamora Polytechnical School, Viriato Campus, \\ University of Salamanca, 49022 Zamora, Spain; arm@usal.es \\ 2 Department of Transportation and Projects and Processes Technology, Civil Engineering Technical School of \\ Santander, University of Cantabria, Los Castros Avenue, 39005 Santander, Spain; vegaa@unican.es (Á.V.-Z.); \\ calzadam@unican.es (M.Á.C.-P.) \\ * Correspondence: eteijon@usal.es
}

Received: 2 July 2020; Accepted: 15 August 2020; Published: 18 August 2020

check for updates

\begin{abstract}
Research has been carried out on recycled aggregates from the exclusive crushing of structural concrete waste (CDWRCon) and mixed ceramic materials (CDWRCer) in selective demolitions. This study analyses the use of these recycled aggregates as wet mix macadam (GARCon, GARCer) and in cement soil (CSRCon, CSRCer). The materials comply with the requirements of a road base; although, due to the low values of resistance to fragmentation, these materials are adequate for use in sensitive road systems and other places, such as urban roads and car parks, that have a low intensity of heavy traffic. As soluble salt contents were detected, additional waterproofing or drainage measures must be adopted to prevent water infiltration into the layers made up of CDWRCon or CDWRCer. Finally, the high initial values of unconfined compressive strength (UCS) allow the temporary passage of light vehicles over CSRCon or CSRCer after three days.
\end{abstract}

Keywords: construction and demolition waste; recycled concrete aggregate; recycled ceramic aggregate; wet mix macadam; cement-soil; sustainable roads

\section{Introduction}

The European Union considers construction and demolition waste (CDW) the largest waste stream, around one third by weight of all waste produced. The Waste Framework Directive 2008/98/EC [1] aims to increase the re-use, recycling, and other forms of CDW recuperation to a minimum of $70 \%$ by weight. This increase means closing the life cycle of construction materials by extending their useful life. For Arshad and Ahmed [2], the increasing difficulties in finding natural aggregates means that extraction costs are increasing. This implies considering the recovery and recycling of old concrete structures as new sources of building materials. Materials containing between $50-75 \%$ recycled asphalt pavement and 5.5-7.5\% aggregates from concrete crushing (CDWRCon) were analysed. The results show the validity of the mixture as a granular base layer. The higher the proportion of CDWRCon, the lower the optimal moisture content in the modified Proctor test. Maximum densities between $20.7-20.3 \mathrm{kN} / \mathrm{m}^{3}$ were obtained. The application of concrete sub-products is limited due to the lack of testing and trials. General use of recycled concrete products in road pavements requires the development of procedures and guidelines with design methods. The Spanish Waste Management Framework Plan [3] establishes a minimum recycling percentage of $90 \%$ for clean soil and stone waste, LER code 170504 [4]. They can be used in earthworks and environmental restoration and conditioning work. Reuse and recycling should be encouraged by encouraging the use of CDWRCon in construction works. Public contracts 
should consider minimum percentages of recycled material in public works, on the order of $5 \%$ for recycled aggregates. In Spain, there is a CDW production of $1 \mathrm{t}$ per inhabitant per year.

For El-Maaty Behiry [5], environmental protection is a major concern in Egypt, where the increase in demolitions provides opportunities to incorporate recycled concrete aggregate into roadways. Unconfined compressive strength (UCS) is the most important quality indicator, with others being cement content, rupture time, or dry density. The recycled concrete aggregates investigated offered a $47^{\circ}$ internal friction angle and a $2.25 \%$ absorption coefficient. A UCS value of $2.56 \mathrm{MPa}$ at seven days was obtained for a 5.0\% cement content. The Catalogue of Pavements and Construction Units with Recycled Aggregates from Construction and Demolition Waste [6] proposes the development of design guidelines or calculation recommendations to facilitate the design for designers. The use of recycled aggregates should be evaluated from environmental aspects, considering the advantage of using CDW as a new resource without the need to consume natural resources. Although there are important differences in the physical, chemical, and mechanical characteristics of recycled aggregates (RAs) compared to natural aggregates, RA (recycled aggregate) can be applied to road pavements partly or fully substituting for natural aggregates. The use of RA in pavement sections has offered a satisfactory performance in sections with a maximum annual average daily traffic of heavy vehicles $\left(\mathrm{vh}_{\mathrm{p}} / \mathrm{d}\right)\left(\mathrm{AADT}_{\mathrm{h}}\right)=800 \mathrm{vhp} / \mathrm{d}$. Values of $\mathrm{E}=500 \mathrm{MPa}$ and $v=0.35$ were estimated for CDWRCon. Cartuxo et al. [7] studied the influence of two superplasticizers (SP) on the durability of concrete made with the fine fraction of CDWRCon. Replacement percentages of $0,10,30,50$, and 100\% were tested. The addition of recycled aggregate increases water absorption by immersion, capillary action, chloride migration coefficient and carbonation depth. The addition of superplasticizer produces a variation in properties. The water/cement ratio decreased by $25 \%$. The absorption decreased by $43 \%$. Water absorption by capillary action at $72 \mathrm{~h}$ decreased to $66 \%$. The carbonation depth at 91 days decreased to $80 \%$. The chloride migration coefficient decreased to $46 \%$. Therefore, the mixture is a sustainable solution that complies with durability requirements. The Guide to the Use of Recycled Aggregates [8] calculates that the construction sector represents half of the materials extracted and energy used and approximately one-third of the water consumed. The modified Proctor test in CDW should be performed after previous saturation. The test should be called the modified Proctor test after saturation. The modified Proctor test after saturation must be performed at least one hour after saturation. This should be the time necessary to assure that the aggregates have completed their water absorption. Thus, for the correct use of CDWRCon on the worksite, the moisture provided during setting and compaction must be determined with the modified Proctor test after saturation. Spanish regulations on roads and structural concrete, such as PG-3 [9] or EHE [10], allow using recycled aggregates. Even so, the requirements are the usual ones for natural aggregates, not encouraging their use in the construction site. Baghini et al. [11] mixed CDW with contents between 0-6\% Portland cement and 0-6\% bitumen emulsion, obtaining exceptional characteristics for use in road bases. Thus, high indices of California bearing ratio (CBR), UCS, and flexural strength were obtained. Specimens were manufactured with $3 \%$ emulsion and $4 \%$ cement, and other samples with $4.0 \%$ cement content. When subjected to 12 wet-dry cycles, the emulsion test specimens showed a $179.4 \%$ water reduction, a $256.3 \%$ volumetric change, and a $211.95 \%$ weight change compared to the other series. According to creep and wheel test results, the deformation resistance is significantly improved with the addition of $4 \%$ cement and 3\% bitumen emulsion. European Regulation (EU) No. 305/2011 [12] requires all RA to carry the CE label (Conformité Européenne). For Agrela et al. [13], there is little research on RA mixed with cement in road pavements despite the environmental benefits of their use. Recycled Aggregates (RA), in comparison with natural aggregates, show lower density, higher water absorption and lower resistance to fragmentation, although this is not important when mixed with cement. The content of soluble sulphates expressed as $\mathrm{SO} 3$ ion should be less than $0.8 \%$ [9] to be mixed with the cement. The South African Department of Transport and Public Works [14], has used a layer of Recycled Aggregates (RA) with $3 \%$ cement as a stabilized soil. 


\section{Materials and Methods}

Research has been focused on recycled aggregate from crushing structural concrete waste in selective demolitions processed at the CDW treatment plant in Calvarrasa de Abajo (Salamanca, Spain). The plant performs treatments for the recovery of CDW, such as crushing, classifying, and separating fractions by triage. The stone fraction of the structural concrete CDW, CDWRCon, rejects the non-stone fraction, soils, stones, and other materials, such as insulations. Thus, CDWRCon is obtained from concrete, concrete products, mortar, and prefabricated concrete parts. The stone fraction with concrete and ceramic materials of CDW, CDWRCer, rejects the non-stone fraction, soils, stones, and other materials, such as insulations. Thus, CDWRCer is obtained from concrete, concrete products, mortar, prefabricated concrete parts, and ceramic materials. Thus, the CDWRCer is a material of continuous granulometry with concrete and ceramic material aggregates.

The ceramic CDW is composed of ceramic brick, mortar, and concrete. Before being crushed, the CDW must be free of improper materials. Examples are metallic materials, plastics, or composite materials such as cement sack containers, composed of sheets of Kraft paper with an intermediate polymer layer. These materials can damage the crusher and cause obstructions that make the production process unviable. Thus, prior to crushing, a $40 \mathrm{~mm}$ screen is established to avoid large sizes, passing the material through a trommel. Later, on a transport belt, a ballistic treatment is applied which consists of the passage of an air current that facilitates the removal and elimination of plastics due to the difference in density. A mechanical treatment with an electromagnet is also applied. By means of an electromagnetic field, scrap metal and metal residues are removed easily and with great performance. Subsequently, a natural post-harvest (triage) is carried out, manually, which guarantees the total elimination of improper waste fractions from the artificial wet mix macadam.

Structural concretes are mostly derived from buildings, usually designed for stresses of $25 \mathrm{MPa}$ at 28 days [10]. It has a dosage composed of natural siliceous aggregate, Portland cement, and chemical additives as fluidizers. This study analyses the use of CDWRCon and CDWRCer in base layers in sustainable road infrastructure and others with similar traffic distributions, such as urban roads, car parks, cycle tracks (exclusive bikeways), or pedestrian routes. Sustainable roads are routes that cross places of great natural value with high environmental limitations on aggregate extraction and that have a low intensity of heavy traffic. Using CDWRCon and CDWRCer as a recycled concrete aggregate (GARCon, GARCer) in a continuous granular base layer was investigated. Using CDWRCon and GARCer in the production of recycled cement soil (CSRCon, CSRCer) was also researched. Thus, granular materials (CDWRCon, CDWRCer), cement, and water were mixed.

The sampling methods to determine the general properties of the aggregates correspond to the Spanish standard UNE-EN 932-1, official version of the European Standard EN 932-1. Thus, different samples have been taken in the material stockpiles, obtaining raw samples that were representative of the average properties of the lots. As there are two different CDW treatment lines, the sampling methods have been applied to the different sample fractions CDWRCon, CDWRCer separately. Representative samples have been obtained for each material investigated in its corresponding conical pile, making a flat stacking by means of an excavator in order to take fractions at different points and at different heights in this way to avoid internal segregations in the stockpile. Finally, in the laboratory, reductions were made to the raw sample by quartering. Thus, in the sampling plan, eight laboratory samples were obtained to carry out the geometric properties of the aggregates by determining the granulometry, evaluating the assessment of fines by the sand equivalent test and determining the particle density and water absorption. Two other samples with the necessary mass were used to determine the classification of the components of the recycled coarse aggregates and to determine resistance to fragmentation. Two laboratory samples were used to determine the compaction test (Modified Proctor) and the mechanical properties of aggregates with the CBR index. At last, for the characterization of aggregates for unbound and hydraulically bound materials for use in structural layers of road pavements, GARCon, and GARCer materials, two laboratory samples were used to manufacture six series of specimens. 
The classification of aggregates for granular layers and those treated with hydraulic conglomerates for use in structural layers of pavements was done in accordance with standard UNE-EN 132442:2003 + A1 [15]. According to the results shown in Table 1, the CDWRCon aggregates, such as GARCon, are classified as $\mathrm{Rcu}_{90}, \mathrm{X}_{1-}, \mathrm{FL}_{1-}$ and the CDWRCer aggregates such a GARCer are classified as Rc 80, $\mathrm{Rcu}_{90}, \mathrm{Rb}_{50-}, \mathrm{Rg}_{2-}, \mathrm{X}_{1-}, \mathrm{FL}_{1-}$.

Table 1. Wet mix macadam (graded aggregate) recycled concrete (GARCon) and wet mix macadam (graded aggregate) recycled ceramic (GARCer) components.

\begin{tabular}{ccccc}
\hline & \multicolumn{2}{c}{ GARCon } & \multicolumn{2}{c}{ GARCer } \\
\hline Components & Contents (\%) & Categories & Contents (\%) & Categories \\
\hline $\mathrm{Rc}$ & 89.7 & $\mathrm{Rc} 80$ & 49.5 & $\mathrm{Rc}_{80}$ \\
$\mathrm{Rc}+\mathrm{Ru}$ & 100 & $\mathrm{Rcu}_{90}$ & 59.7 & $\mathrm{Rcu}_{90}$ \\
$\mathrm{Rb}$ & - & - & 39.7 & $\mathrm{Rb}_{50-}$ \\
$\mathrm{Rg}$ & - & - & 0.6 & $\mathrm{Rg}_{2-}$ \\
$\mathrm{X}$ & $<0.1$ & $\mathrm{X}_{1-}$ & $<0.1$ & $\mathrm{X}_{1-}$ \\
$\mathrm{FL}$ & $<0.1$ & $\mathrm{FL}_{1-}$ & $<0.1$ & $\mathrm{FL}_{1-}$ \\
\hline
\end{tabular}

where: $\mathrm{Rc}=$ concrete, concrete products, mortar and concrete masonry parts. $\mathrm{Ru}=$ untreated aggregates and natural stone aggregates treated with hydraulic binders. $\mathrm{Rb}=$ parts for clay (bricks and tiles) and calcium silicate masonry. Non-floating aerated concrete. $\mathrm{Rg}=$ glass. $\mathrm{FL}=$ Floating material in volume. $\mathrm{X}=$ Other: cohesive materials (clay and soil), metals (ferrous and non-ferrous), wood, gypsum, non-floating plastics and rubber.

The GARCon and GARCer components can be seen in Figure 1a,b.

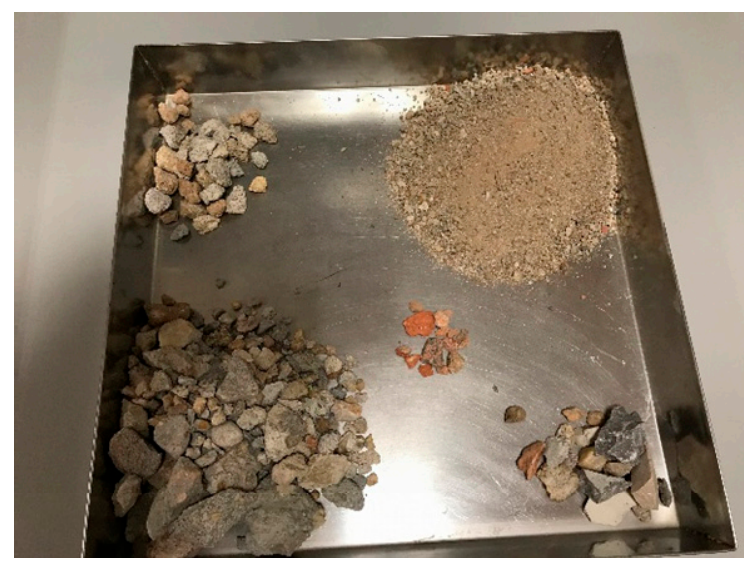

(a)

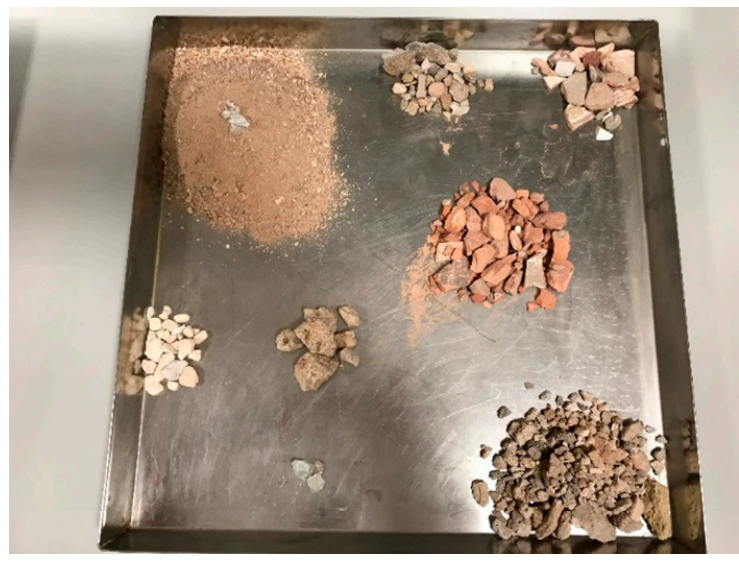

(b)

Figure 1. (a) GARCon components (b). GARCer components.

Table 2 shows the distribution of particles. In GARCon, values of $\mathrm{Cu}=75.0$ and $\mathrm{Cc}=3.1$ were obtained. The high value of the uniformity coefficient shows the high size variation obtained in the unclassified crushing. The curvature coefficient defines the GARCon and the GARCer as well-graded and with high compactness.

Table 2. Aggregate type and particle size distribution characteristics of the GARCon and GARCer.

\begin{tabular}{lcccccccccc}
\hline Material & $\begin{array}{c}\mathbf{D}_{\mathbf{1 0}} \\
(\mathbf{m m})\end{array}$ & $\begin{array}{c}\mathbf{D}_{\mathbf{3 0}} \\
(\mathbf{m m})\end{array}$ & $\begin{array}{c}\mathbf{D}_{\mathbf{5 0}} \\
(\mathbf{m m})\end{array}$ & $\begin{array}{c}\mathbf{D}_{\mathbf{6 0}} \\
(\mathbf{m m})\end{array}$ & $\mathbf{C}_{\mathbf{u}}$ & $\mathbf{C}_{\mathbf{c}}$ & $\begin{array}{c}\text { \% } \\
\text { Fines }\end{array}$ & $\begin{array}{c}\text { \% Sand } \\
\text { Size }\end{array}$ & $\begin{array}{c}\text { \% (4.75-9.5) } \\
\mathbf{m m}\end{array}$ & $\begin{array}{c}\text { \% (9.5-40) } \\
\mathbf{m m}\end{array}$ \\
\hline GARCon & 0.08 & 1.0 & 4.0 & 6.0 & 75.0 & 3.1 & 11.1 & 56.1 & 11.9 & 32.0 \\
GARCer & 0.12 & 1.0 & 4.5 & 8.5 & 70.8 & 1.0 & 8.8 & 49.4 & 11.0 & 39.6 \\
\hline
\end{tabular}

The granulometric curves of the GARCon and GARCer, according to standard UNE EN 933-1 [16], are shown in Figure 2. The tolerance curve for ZA 0/20 [9], which is the artificial grading with a 
minimum size of $0 \mathrm{~mm}$ and a maximum of $20 \mathrm{~mm}$, is also included. The granulometric curve of the GARCon and GARCer complies with the specifications of ZA 0/20 grading. The tolerances [6] are $\pm 2 \%$ for the $0.063 \mathrm{~mm}$ and $\pm 6 \%$ for the rest. In the GARCon, the $2 \mathrm{~mm}$ sieve is $3.5 \%$ above the $2 \mathrm{~mm}$ sieve and $1.0 \%$ on the $0.063 \mathrm{~mm}$ sieve, so the tolerances are satisfied in GARCon. The curve takes the typical shape of crushing siliceous aggregates, with a deficit of intermediate sizes in the sand fraction on the \#2 mm sieve. In the case of GARCer, all the gradings comply with the specifications of the ZA 0/20 grading without needing the tolerances.

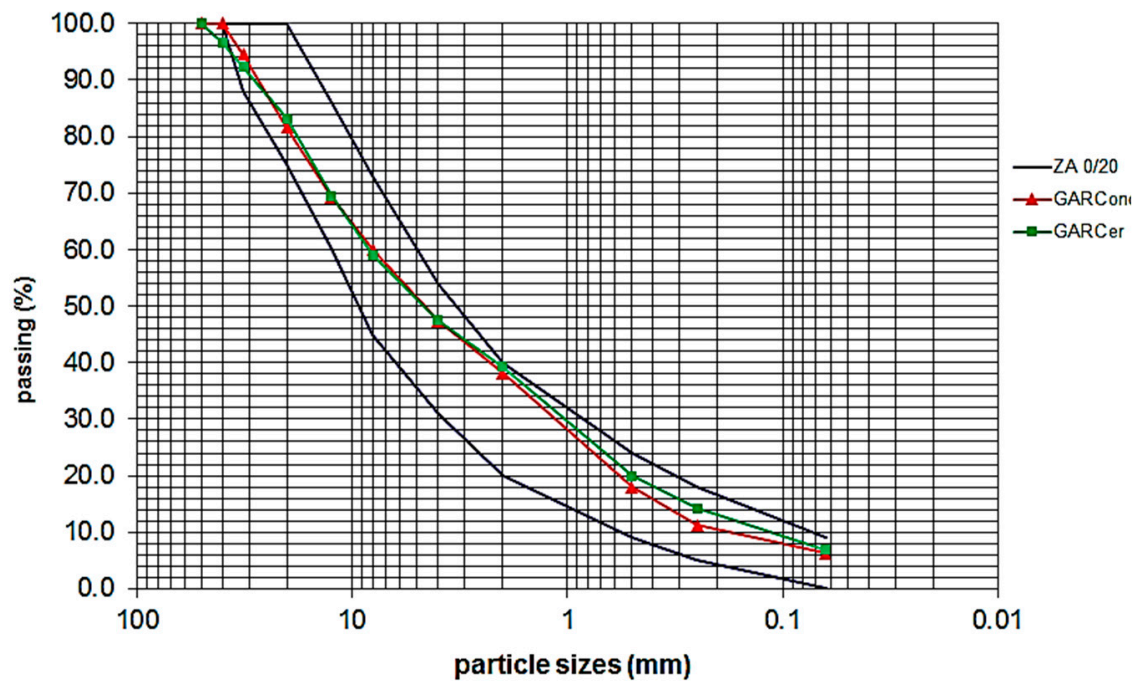

Figure 2. GARCon, GARCer, and ZA 0/20 granulometric curves.

In both cases, the heterogeneity of the material, coming from the crushing of different types of concrete and ceramic materials, makes it difficult to obtain average granulometries. GARCon and GARCer are classified as GA 75 [15], which are crushed gravels with a minimum size of $0 \mathrm{~mm}$ and a pass through the sieve of $6.3 \mathrm{~mm}$ between $75-99 \%$. The main physical and chemical parameters of the GARCon and GARCer are shown in Table 3.

Table 3. Physical and chemical parameters for GARCon, GARCer.

\begin{tabular}{|c|c|c|c|c|c|c|c|c|c|c|}
\hline Material & $\mathrm{SE}_{4}$ & LA & OM & SS & $\begin{array}{c}\mathrm{d}_{\mathrm{c}} \\
\left(\mathrm{g} / \mathrm{cm}^{3}\right)\end{array}$ & $\begin{array}{c}d_{f} \\
\left(g / \mathrm{cm}^{3}\right)\end{array}$ & $\begin{array}{l}\mathrm{AC}_{\mathrm{c}} \\
(\%)\end{array}$ & $\begin{array}{l}\mathrm{AC}_{\mathrm{f}} \\
(\%)\end{array}$ & LL & PI \\
\hline GARCon & 47.0 & 43.0 & 0.14 & 1.1 & 2.623 & 2.606 & 6.2 & 4.0 & $\mathrm{NL}$ & $\mathrm{NP}$ \\
\hline GARCer & 31.0 & 52.0 & - & - & 2.510 & 2.624 & 10.7 & 4.3 & - & - \\
\hline
\end{tabular}

where: $\mathrm{SE}_{4}=$ sand equivalent, UNE-EN 033-8 [17]. LL = liquid limit UNE 103103 [18]. PI = plastic limit UNE 103104 [19]. LA = Los Angeles coefficient, UNE-EN 1097-2 [20]. OM = organic matter content, UNE 1032204 [21]. SS = soluble salt content, UNE 103205 [22]. $\mathrm{d}_{\mathrm{c}}=$ particle density coarse aggregate, UNE-EN 1097-6 [23]. $\mathrm{d}_{\mathrm{f}}=$ particle density fine aggregate, UNE-EN 1097-6 [23]. $\mathrm{AC}_{\mathrm{f}}=$ water absorption fine aggregate, UNE-EN 1097-6 [23]. $\mathrm{AC}_{\mathrm{c}}=$ water absorption coarse aggregate, UNE-EN 1097-6 [23].

The quality of the fines, expressed as $\mathrm{SE}_{4}$ sand equivalent, gives a value of 47.0 in GARCon, satisfying the required values in granular layers. The sand equivalent in GARCer is 31.0, less than GARCon; this difference is motivated by the existence of parts for clay (bricks and tiles) and calcium silicate masonry that reduces the sand lecture and $\mathrm{SE}_{4}$ value. The Atterberg limits classify GARCon as not plastic. Fragmentation resistance offers an LA coefficient of 43.0 for GARCon. This value complies with the maximum recommended threshold [9] for an AADTh of less than $50 \mathrm{vhp} / \mathrm{d}$, as is usually found in road systems in sensitive environments. The resistance to fragmentation in GARCer, with LA $=52.0$, is lower than GARCon, motivated by the presence of bricks, tiles, and calcium silicate masonry.

The organic matter test provided a $0.14 \%$ value in GARCon. The content of soluble salts dissolved in distilled water for GARCon was 1.1\%. Thus, additional waterproofing or drainage measures should 
be adopted in the upper layers of the pavement to avoid water infiltration into the layer formed with GARCon. The specific weight of the coarse particles was $2.623 \mathrm{~g} / \mathrm{cm}^{3}$ in GARCon and $2.510 \mathrm{~g} / \mathrm{cm}^{3}$ in GARCer. The big value of GARCon is associated with a larger presence of concrete and concrete products. In contrast, the particle density of fine aggregate was 2.606 in GARCon and 2.624 in GARCer. In this case, there is a larger density value in GARCer fine fraction, associated with the origin from bricks, tiles, and calcium silicate masonry.

The CDW has a high-water absorption coefficient, higher than that of natural aggregates. In the CDWRCon, the high absorption was associated with the porosity of the concrete, which is the main component. The water absorption coefficients are bigger in GARCer in any case. Thus, in the coarse fraction, the absorption coefficient was $6.2 \%$ in GARCon and $10.7 \%$ in GARCer. This high difference of $4.5 \%$ is associated with the high absorption of clay materials, such as bricks and tiles. The fine fractions have absorption coefficients with similar values for both materials, $4.0 \%$ in the case of GARCon and $4.3 \%$ in GARCer, only $0.3 \%$ difference.

The standard deviations of the sample, as an average of the results obtained in the tests, have been appropriate for the standard deviations of CDW materials, for which reason the number of extractions carried out has been sufficient.

\section{Results and Discussion}

The curves of the modified Proctor test, UNE 103501 [24], which can be seen in Figure 3, offer a maximum density of $1.992 \mathrm{~g} / \mathrm{cm}^{3}$ and an optimum moisture content of $10.6 \%$ for GARCon, and a maximum density of $1.861 \mathrm{~g} / \mathrm{cm}^{3}$ and optimum moisture content of $12.1 \%$ in GARCer. The material with high quality and less fine fraction, GARCon, has more maximum density and less moisture content than GARCer. The shape of the curve is practically horizontal; variations in moisture produce small increases in density due to the high absorption.

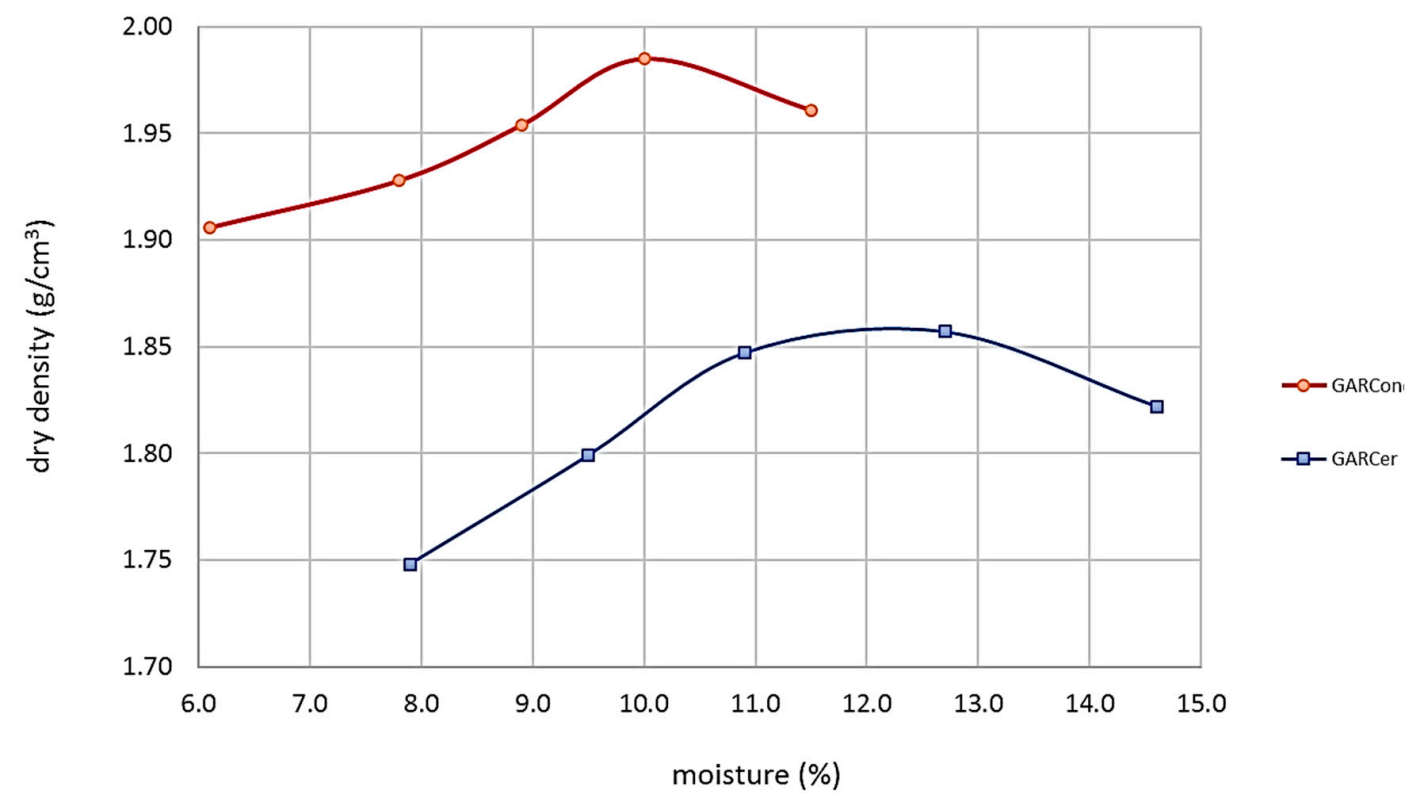

Figure 3. GARCon and GARCer modified Proctor.

To achieve a $100 \%$ compaction degree for the modified Proctor test on the construction site, the GARCon and GARCer must be previously watered. A humidity correction must be performed, providing an excess of water above the optimum equal to the absorption coefficient.

Figure 4 shows the different gradings between the curves in GARCon for the modified Proctor test (substitution of sizes bigger than $20 \mathrm{~mm}$ by $0 / 20 \mathrm{~mm}$ material) before and after the compaction test. The low fragmentation resistance of GARCon produces, after the compactor mace, an increase of 
percentages at any sieve. The main differences are in the $2 \mathrm{~mm}$ sieve, with $11.1 \%$ more after compaction, and $0.4 \mathrm{~mm}$ sieve, with $6.6 \%$. In any case, the coarse fraction also increases, with $5.0 \%$ in the $12.5 \mathrm{~mm}$ sieve. In contrast, there is a little rise of $1.5 \%$ for the filler fraction.

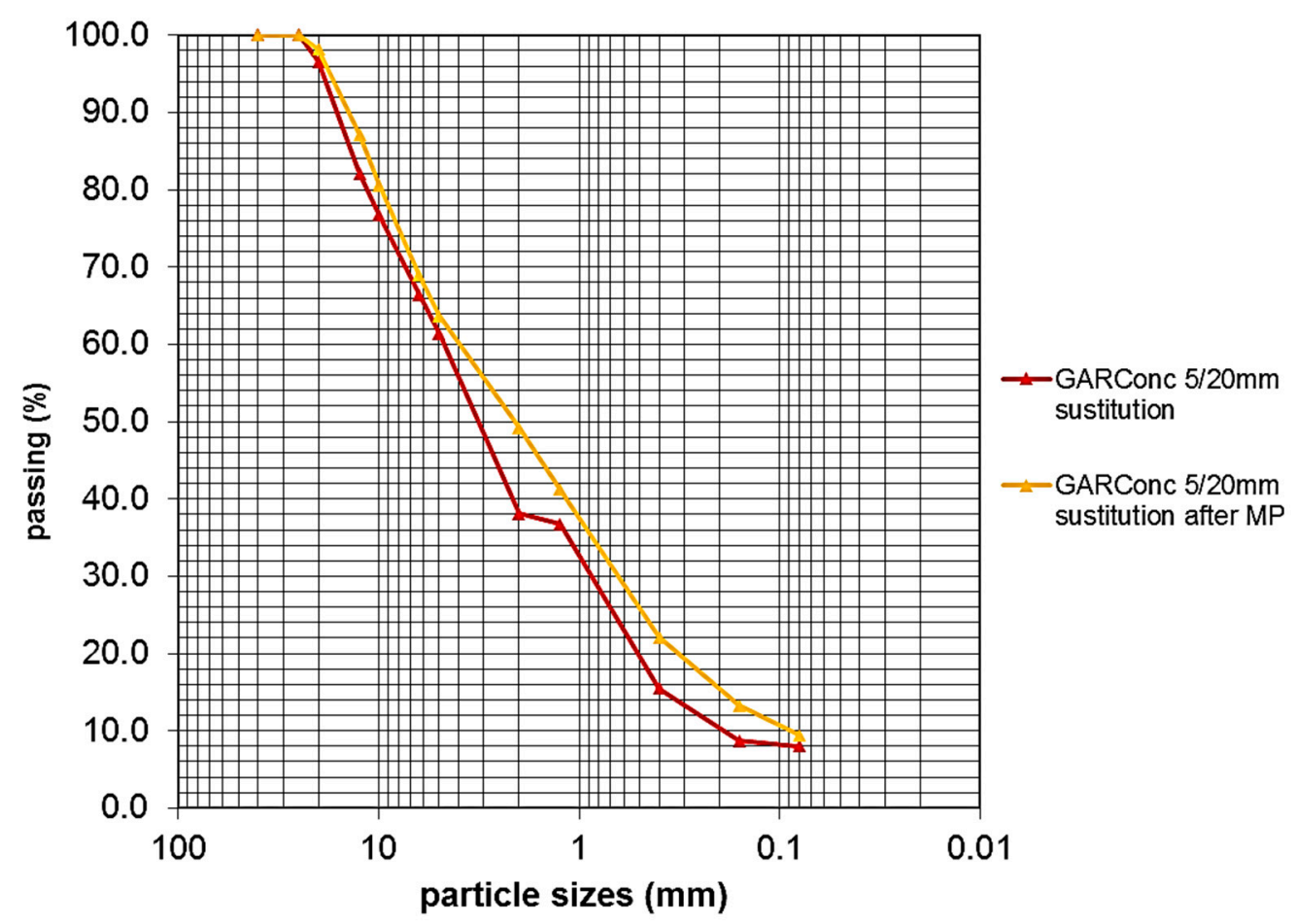

Figure 4. GARCon substitution granulometric curve before and after the modified Proctor test.

Identically, Figure 5 shows the different gradings between the curves in GARCer for the modified Proctor test (with the substitution), before and after the compaction test. The lowest fragmentation resistance of GARCer produces a bigger increase in percentages. The main differences are in the $2 \mathrm{~mm}$ sieve too, with $16.5 \%$ more after compaction, and $0.4 \mathrm{~mm}$ sieve with $3.7 \%$. In any case, the coarse fraction also increases more than GARCon, with $11.9 \%$ on the $12.5 \mathrm{~mm}$ sieve. In this case, there is also a small rise of filler fraction of $1.2 \%$ for GARCer.

The discontinuous particle size set out in the modified Proctor test standard, resulting from the replacement of sizes larger than $20 \mathrm{~mm}$, improves after test compaction in both materials, which become more uniform and continuous. This increase in compactness is more pronounced in the GARCer. As can be seen in Figure 6, the CBR index, UNE 103502 [25], for a 100\% degree of compaction for the modified Proctor density is 193.0. GARCon has a high bearing capacity, suitable for use as a granular base layer. Similarly, the CBR index for a 100\% is 164.0, so GARCer has a high bearing capacity too. 


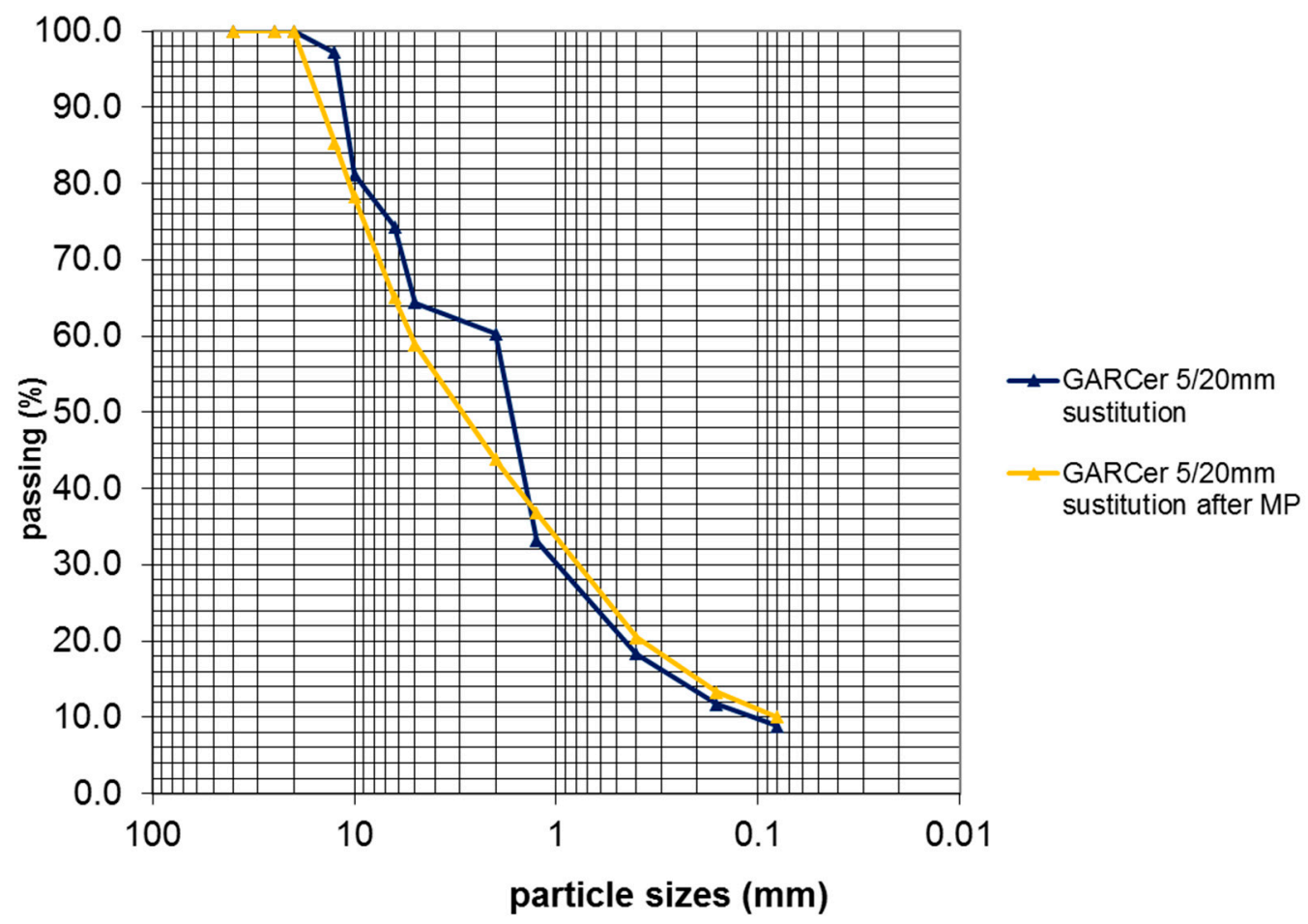

Figure 5. GARCer substitution granulometric curve before and after modified Proctor curves.

Another use of the CDWRCon and CDWRCer is the manufacture of soil-cement, CSRCon and CSRCer, as a structural layer in road pavements. The chemical composition of CDWRCon and its non-plastic character are suitable for soil-cement. As can be seen in Figure 7, the granulometric test classifies the CSRCon and CSRCer as SC40 in accordance with [6]. The existence of a coarse fraction in both cases, upper 80 to $100 \%$ screening by the $40 \mathrm{~mm}$ sieve, allows for use below the pavement level.

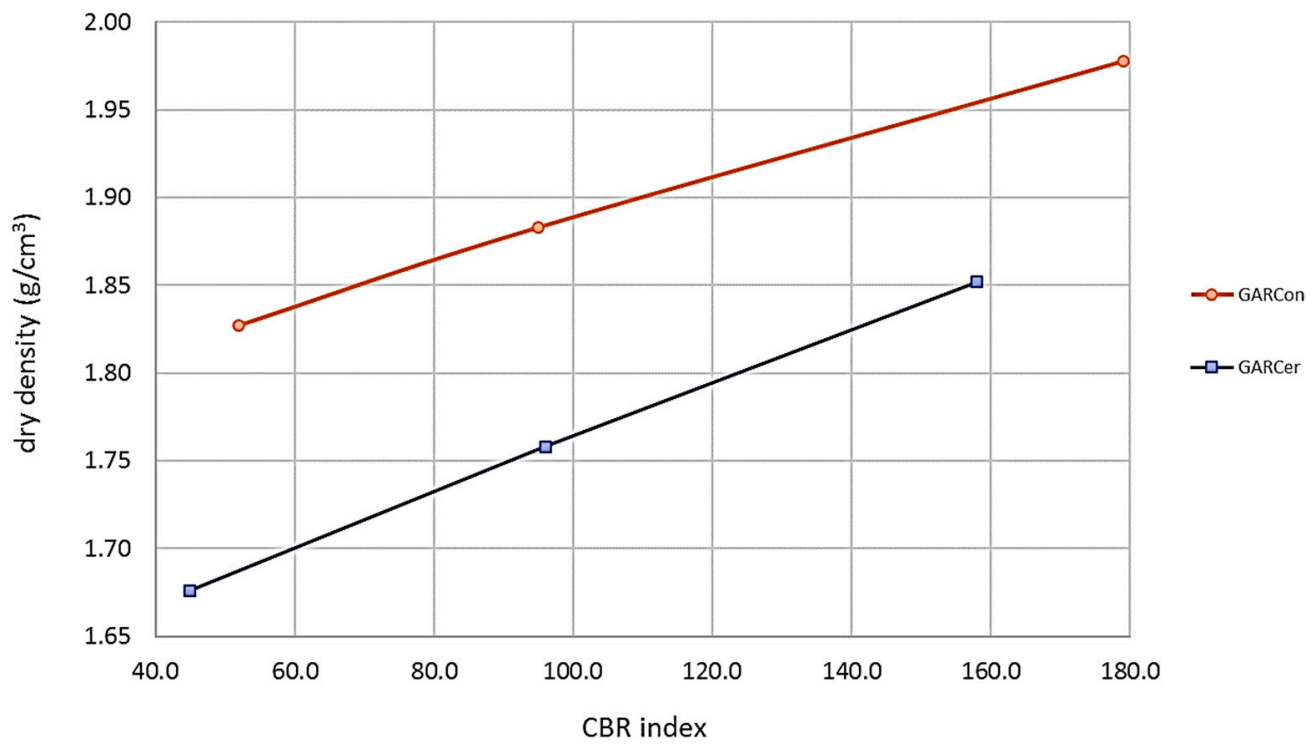

Figure 6. GARCon and GARCer California bearing ratio (CBR) index. 


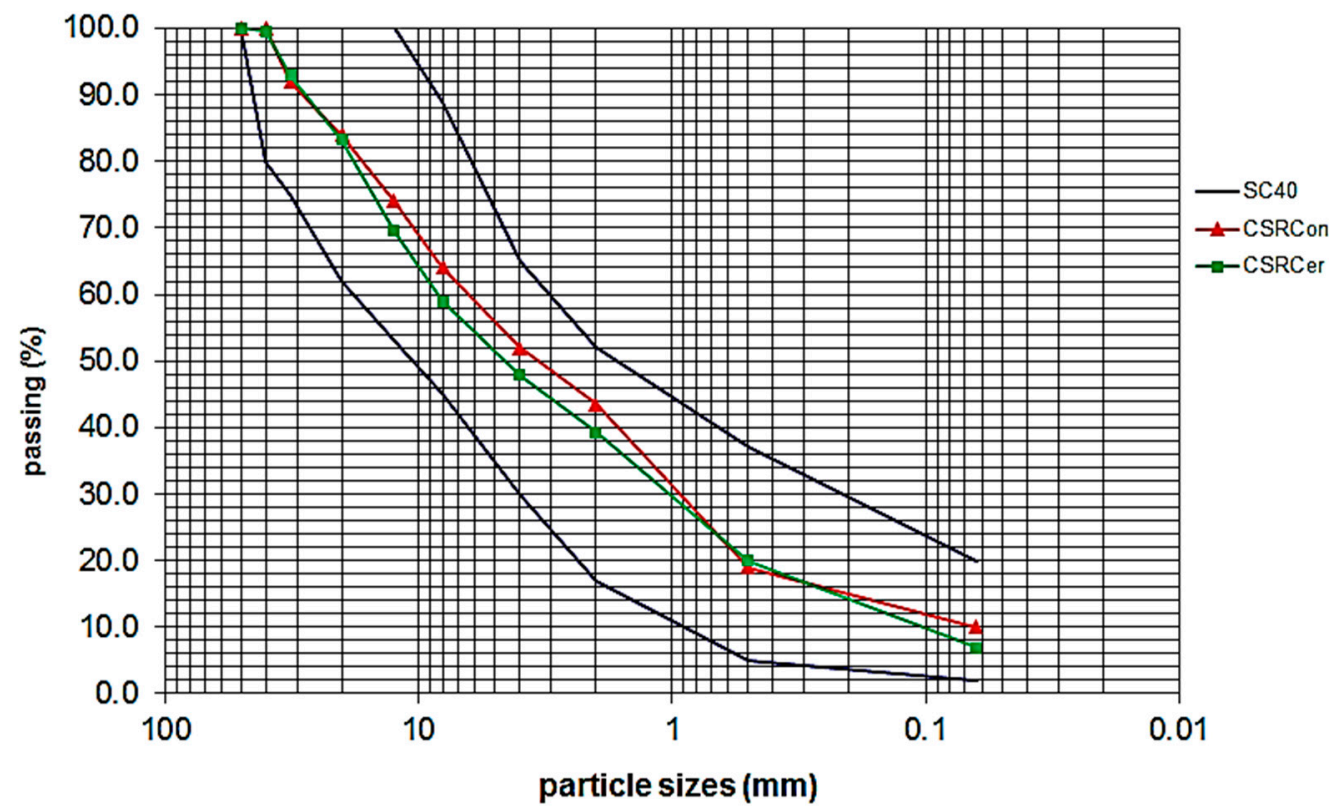

Figure 7. Cement soil recycled concrete (CSRConc), cement soil recycled ceramic (CSRCer) and cement soil with a maximum size of $40 \mathrm{~mm}$ (SC40) granulometric curves.

The binder used was cement type CEMII/B-M (V-L) 32.5R [26]. It is a composite Portland cement, with a clinker content between $65-79 \%$ and $21-35 \%$ of additions such as siliceous fly ash and limestone. The modified Proctor of the mixtures is shown in Figure 8, with values of $2.023 \mathrm{~g} / \mathrm{cm}^{3}$ maximum density and $8.0 \%$ optimum moisture for CSRCon and $1.861 \mathrm{~g} / \mathrm{cm}^{3}$ maximum density and $12.1 \%$ optimum moisture for CSRCer. This implies that the quality of CSRCer is less than CSRCon because it has $0.162 \mathrm{~g} / \mathrm{cm}^{3}$ density less and optimum moisture $4.1 \%$ over.

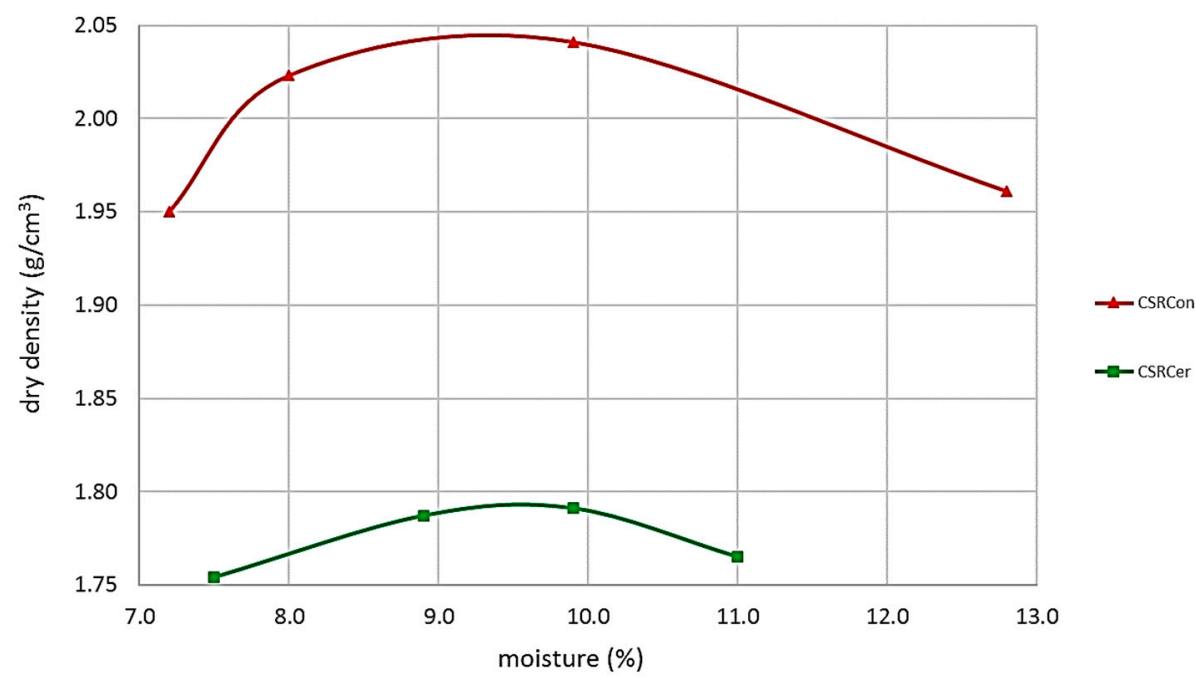

Figure 8. CSRCon and CSRCer modified Proctor.

The curves of the modified Proctor test at CSRCon and CSRCer are also horizontal, behaviour associated with the absorption of the aggregates. For CSRCer, with the larger water absorption coefficients, with a difference of $4.5 \%$ in coarse aggregate, the curve has fewer variations and it is practically horizontal, with minimal increases of dry density with moisture increases. 
Table 4 shows the modified Proctor results for both materials (concrete, ceramic) without any addition (GAR, wet mix macadam) and with a cementitious binder (CSR cement soil). It shows that the concrete has higher densities than ceramics in any case. However, the moistures of ceramic materials are always larger. In concrete, the cement stabilization produces a high density $\left(+0.30 \mathrm{~g} / \mathrm{cm}^{3}\right)$ and the optimum humidity decreases $(-2.6 \%)$. In contrast, the density in ceramic material decreases with cement addition, which could be motived to a granulometric variation, probably associated with the heterogeneity of the recycled materials with very different origins. Together with this, the density variation is only $-0.71 \mathrm{~g} / \mathrm{cm}^{3}$, practically a horizontal line, obtaining the same density values for moisture contents of 9.4 and $12.1 \%$. The optimum water content decreases $(-2.7 \%)$ with the cement addition in ceramic, with the same tendency as concrete and traditional soil-cement materials.

Table 4. Modified Proctor variations.

\begin{tabular}{ccccc}
\hline & \multicolumn{2}{c}{ Concrete Waste } & \multicolumn{2}{c}{ Ceramic Waste } \\
\hline Material & $\mathrm{d}_{\max }\left(\mathrm{g} / \mathrm{cm}^{3}\right)$ & $\mathrm{h}_{\mathrm{opt}}(\%)$ & $\mathrm{d}_{\max }\left(\mathrm{g} / \mathrm{cm}^{3}\right)$ & $\mathrm{h}_{\mathrm{opt}}(\%)$ \\
wet mix macadam & 1.992 & 10.6 & 1.861 & 12.1 \\
cement soil & 2.023 & 8.0 & 1.790 & 9.4 \\
\hline
\end{tabular}

where: $\mathrm{d}_{\max }=$ Modified Proctor maximum dry density $\left(\mathrm{g} / \mathrm{cm}^{3}\right)$, UNE 103501 [24]. $\mathrm{h}_{\mathrm{opt}}=$ Modified Proctor optimum water content (\%), UNE 103501 [24].

The manufactured specimens of CSRCon and CSRCer have a cement content of $3.0 \%$ with ruptures at 3,7 , and 28 days. This cement percentage was determined by looking for the optimization of these materials with a high CBR index. The specimens were compacted with an energy corresponding to $98 \%$ of the modified Proctor. Figure 9 shows the Unconfined Compressive Strength (UCS) values obtained at different ages $(3,7$, and 28 days). In both cases, the best fits were a logarithmic curve, models that capture the largest increases in initial resistances. The high initial values of UCS $>1.5 \mathrm{MPa}(3 \mathrm{~d})$, $2.73 \mathrm{MPa}$ in CSRCon and $1.87 \mathrm{MPa}$ in CSRCer, allow the temporary passage of light vehicles through the roadbed made with CSRCon three days after paving.

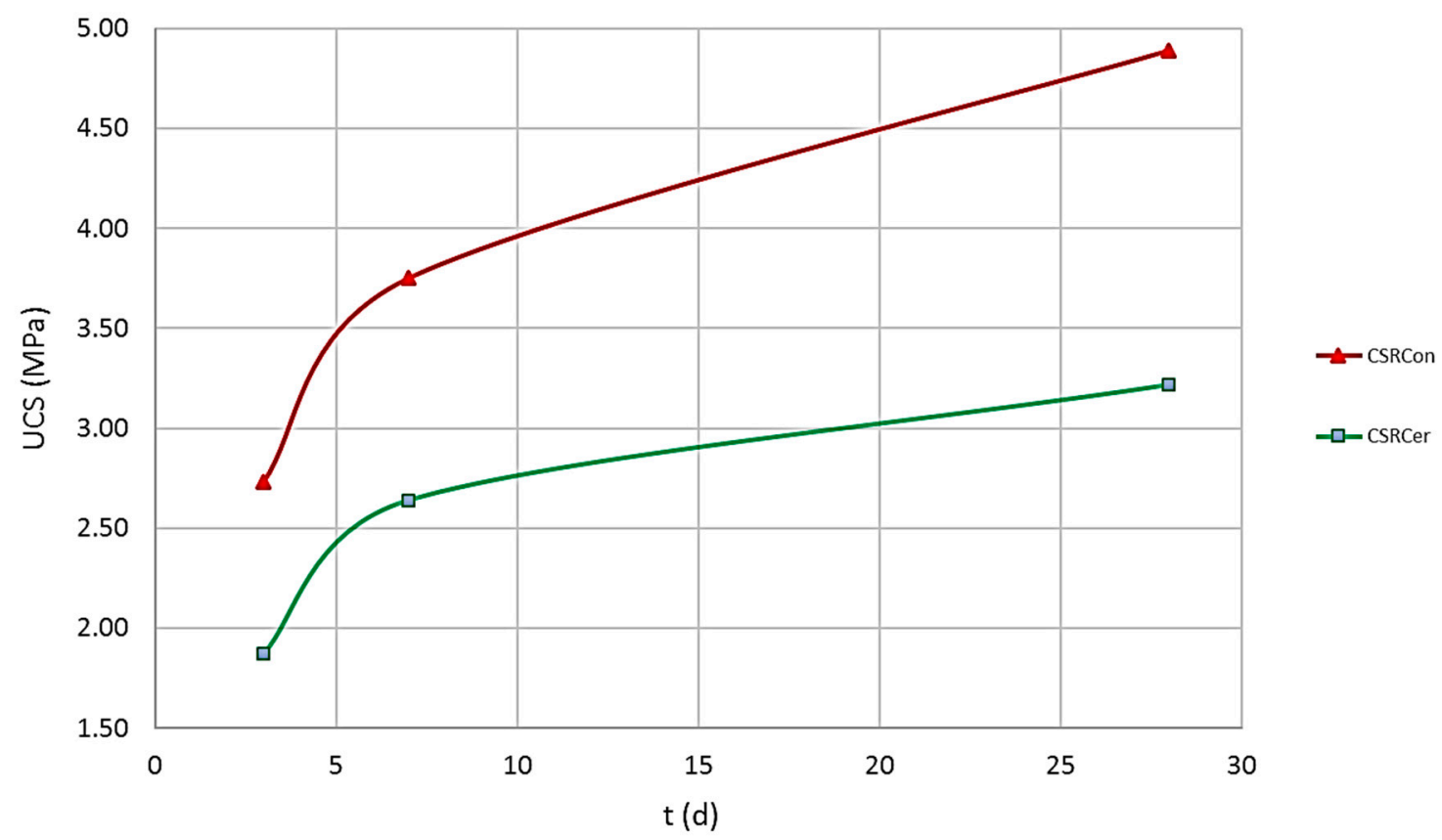

Figure 9. CSRConc and CSRCer UCS curve. 
The equations that have been adjusted for a CSRConc and CSRCer UCS versus time model were:

$$
\begin{array}{ll}
\mathrm{UCS}_{\text {Conc }}=0.9529 \ln (\mathrm{t})+1.7646 & \mathrm{R}^{2}=0.9887 \\
\mathrm{UCS}_{\text {Cer }}=0.5832 \ln (\mathrm{t})+1.3307 & \mathrm{R}^{2}=0.9526
\end{array}
$$

with the UCS in MPa and the time in days. The function has a domain for UCS between 2.7-4.9 MPa for CSRConc and 1.87-3.22 MPa for CSRCer. The domain for rupture time is 3-28 days in both materials. The UCS values meet the requirements as a base layer for pavements [9], UCS $\geq 2.5 \mathrm{MPa}(7 \mathrm{~d})$, clearly complied for CSRCon (+ 1.25) and more adjusted in CSRCer (+ 0.14).

Figure 10 shows the ratio d-UCS. It is proportional in both materials with the higher values of $d$ and UCS corresponding. The dry density versus UCS was fitted with logarithmic models. The equations that were adjusted for both materials were:

$$
\begin{array}{ll}
\mathrm{UCS}_{\text {Con }}=98.27 \ln (\mathrm{d})-64.82 & \mathrm{R}^{2}=0.6262 \\
\mathrm{UCS}_{\text {Cer }}=81.28 \ln (\mathrm{d})-44.428 & \mathrm{R}^{2}=0.5707
\end{array}
$$

with the UCS in MPa and the dry density (d) in $\mathrm{g} / \mathrm{cm}^{3}$. The function has a domain for UCS between 2.7-4.9 MPa for CSRCon and 1.87-3.22 MPa for CSRCer. The domain for dry density was 1.941-2.025 $\mathrm{g} / \mathrm{cm}^{3}$ in CSRCon and $1.767-1.792 \mathrm{~g} / \mathrm{cm}^{3}$ in CSRCer.

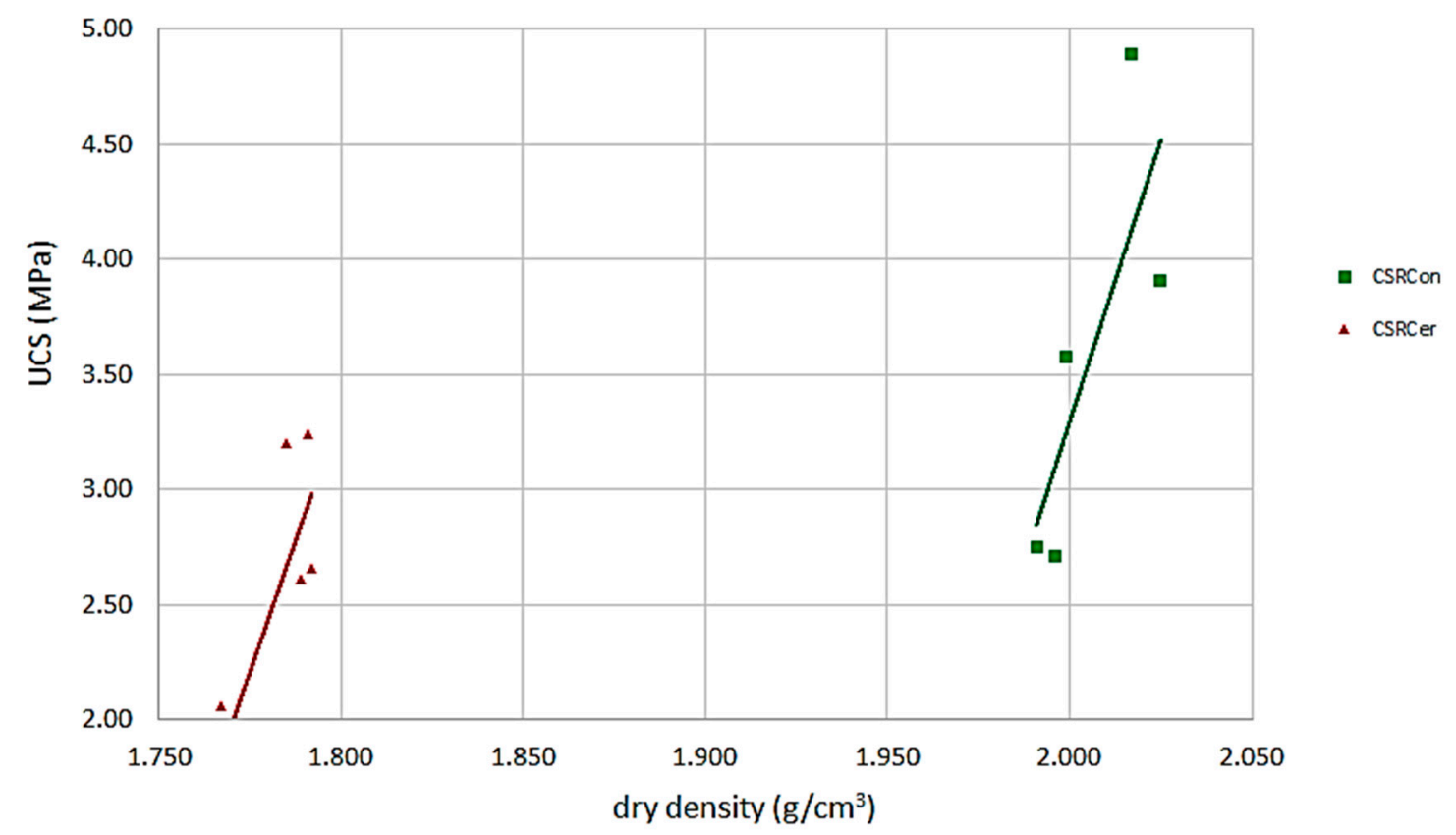

Figure 10. Relationship between dry density-UCS in CSRConc and CSRCer.

Nowadays, the use of recycled construction materials as part of a sustainable circular economy is a main line of research as a substitute for traditionally used materials. The use of recycled construction materials as part of a sustainable circular economy is currently a major line of research to replace traditionally used materials. This research extends the investigations undertaken, applying the use of CDWs to different pavement layers and adapting their characteristics to sustainable roads with low traffic intensity.

The advantage of the proposed solutions over other investigations is the use of CDW in the lower layers of the pavement and not only in esplanades or foundations as in others research. Also, the use of different types of recycled aggregates (concrete, ceramic), facilitates the circular economy through 
the production and use of different types of CDW in civil works. As a disadvantage, the processing of CDWCer, since it has ceramic materials in its composition, requires an intense quality control in its reception on site.

\section{Conclusions}

This research studied the use in road infrastructures of CDWRCon and CDWRCer. The CDWRCon is the construction and demolition waste (CDW) stone fraction corresponding to concrete, which is obtained by crushing structural concrete, concrete products, mortar, and prefabricated concrete parts. The CDWRCer is the CDW with additional parts for clay (bricks and tiles) and calcium silicate masonry. Among the possible uses, the use in pavement base layers as artificial grading (GARCon, GARCer) and recycled cement soil (CSRCon, CSRCer) was investigated.

The results obtained recommend the use of GARCon in sustainable road infrastructures, which are routes that cross places of great natural value with high environmental limitations on aggregate extraction and that have a low intensity of heavy traffic $\left(<0 \mathrm{vh}_{\mathrm{h}} / \mathrm{d}\right)$, roads in urban roads, and parking lots. The high value of Los Angeles coefficient in CDWRCer $(>50)$ advises avoiding using GARCer in sustainable road infrastructures.

The following conclusions have been obtained:

- The CDWRCon can be classified as $\mathrm{Rcu}_{90}, \mathrm{X}_{1-}, \mathrm{FL}_{1}$, containing concrete, concrete products, mortar, concrete masonry pieces, untreated aggregates, natural stone, and aggregates treated with hydraulic conglomerates greater than $90 \%$ and less than $1 \%$ of floating material and other materials.

- $\quad$ The CDWRCer aggregates are classified as $\mathrm{Rc} 80, \mathrm{Rcu} 90, \mathrm{Rb}_{50-}, \mathrm{Rg}_{2-}, \mathrm{X}_{1_{-},}, \mathrm{FL}_{1-}$, containing concrete, concrete products, mortar, concrete masonry pieces, untreated aggregates, natural stone, and aggregates treated with hydraulic conglomerates greater than $90 \%$, parts for clay (bricks and tiles) and calcium silicate masonry and non-floating aerated concrete greater than $50 \%$, glass fraction greater than $2 \%$, and finally less than $1 \%$ of floating material and other materials.

- The modified Proctor test for GARCon and GARCer lacks sensitivity. There are small variations in density for different moistures, behaviour associated with the high absorption coefficient of fine and graded fractions, especially in GARCer $\left(\mathrm{AC}_{\mathrm{C}}=10.7 \%\right)$.

- Tests of CDWRCon and CDWRCer show the quality of the fines and their non-plastic character, the low organic matter content and a high CBR value.

- The GARCon wet mix macadam, made of CDWRCon, is classified as ZA 0/20 and GA 75, with a screening of $75-100 \%$ by the $20 \mathrm{~mm}$ sieve. Tests prove the adequacy of the material as a granular base layer. The high value of CBR index permits considering using GARCer in sustainable road infrastructures, promoting the sustainability and recycling of CDWRCer.

- The CSRCon and CSRCer were classified as SC40 cement soil, with screening between $80-100 \%$ through the $40 \mathrm{~mm}$ sieve. High values of UCS $>2.5 \mathrm{MPa}$ (7d) were obtained for a cement content of $3.0 \%$, demonstrating the use as a base layer on the roadbed. The high initial UCS values at the CSRCon, UCS > $1.5 \mathrm{MPa}$ (3d), allows the transit of light vehicles over the platform after three days.

- The results obtained in the use of CDW must always be associated with high environmental benefits as a sustainable solution, based on the reutilization, valorization and reduction of consumed energy and limited natural resources. Even with the possible variations in the CDW of the component fractions of the recycled coarse aggregates, working formulas can be established that guarantee the specified compaction and mechanical resistance. As future lines of research, test sections can be carried out to verify, with the limitations of execution inherent to recycled materials, the performance of the research developed.

Author Contributions: Data curation, E.T.-L.-Z. and Á.R.-M.; formal analysis, E.T.-L.-Z.; investigation, E.T.-L.-Z. and Á.R.-M.; methodology, E.T.-L.-Z.; project administration, E.T.-L.-Z.; resources, Á.R.-M.; software, E.T.-L.-Z. and Á.R.-M.; supervision, E.T.-L.-Z., Á.V.-Z. and M.Á.C.-P.; validation, E.T.-L.-Z., Á.V.-Z. and M.Á.C.-P.; 
writing-original draft, E.T.-L.-Z.; writing-review and editing, E.T.-L.-Z., Á.V.-Z. and M.Á.C.-P. All authors have read and agreed to the published version of the manuscript.

Funding: This research received no external funding.

Conflicts of Interest: The authors declare no conflict of interest.

\section{Abbreviations}

The following abbreviations are used in this manuscript:

RA Recycled aggregate.

CDW Construction and demolition waste.

CDWRCon Construction and demolition waste from recycled concrete.

CDWRCer Construction and demolition waste from recycled ceramic.

GARCon Wet mix macadam (Graded Aggregate) recycled concrete.

GARCer Wet mix macadam (Graded Aggregate) recycled ceramic.

E Compressive modulus (MPa).

$v \quad$ Poisson coefficient.

$\mathrm{Cu} \quad$ Uniformity coefficient.

Cc Curvature coefficient.

ZA 0/20 Wet mix macadam with minimum and maximum sizes of 0 and $20 \mathrm{~mm}$.

$\mathrm{GA}_{75} \quad$ Aggregate combined with a passage through the largest sieve of 75-99\%.

CBR California bearing ratio.

CSRCon Cement soil recycled concrete.

CSRCer Cement soil recycled ceramic.

SC40 Cement soil with a maximum size of $40 \mathrm{~mm}$.

$\mathrm{UCS}_{\mathrm{Con}} \quad$ Unconfined compressive strength of CSRCon (MPa).

$\mathrm{UCS}_{\mathrm{Cer}} \quad$ Unconfined compressive strength of CSRCer (MPa).

$\mathrm{SE}_{4} \quad$ Sand equivalent.

LL Liquid limit.

PI Plastic limit.

LA Los Angeles wear coefficient.

OM Organic matter content (\%).

SS Soluble salt content (\%).

d Particle density $\left(\mathrm{g} / \mathrm{cm}^{3}\right)$.

AC Water absorption (\%).

$\mathrm{AADT}_{\mathrm{h}} \quad$ Annual average daily traffic of heavy vehicles $\left(\mathrm{vh}_{\mathrm{p}} / \mathrm{d}\right)$

$v_{h} \quad$ Heavy vehicles.

$\mathrm{d}_{\max } \quad$ Modified Proctor maximum dry density $\left(\mathrm{g} / \mathrm{cm}^{3}\right)$.

$h_{\text {opt }} \quad$ Modified Proctor optimum water content (\%).

\section{References}

1. Directive, E.C. Directive 2008/98/EC of the European Parliament and of the Council of 19 November 2008 on waste and repealing certain Directives. Off. J. Eur. Union. 2008, 3, 312.

2. Arshad, M.; Ahmed, M.F. Potential use of reclaimed asphalt pavement and recycled concrete aggregate in base/subbase layers of flexible pavements. Constr. Build. Mater. 2017, 151, 83-97. [CrossRef]

3. Spanish Waste Management Framework Plan 2016-2022 PEMAR. 2015. Available online: https://tinyurl.com/ y3k35sun (accessed on 15 May 2020).

4. Directive, E.C. Amending Decision 2000/532/EC on the list of waste pursuant to Directive 2008/98/EC of the European Parliament and of the Council, 18 December 2014. Off. J. Eur. Union 2000. Available online: https://tinyurl.com/yyaepybz (accessed on 15 May 2020).

5. Ebrahim Abu El-Maaty Behiry, A. Utilization of cement treated recycled concrete aggregates as base or subbase layer in Egypt. Ain Shams Eng. J. 2013, 4, 661-673. [CrossRef]

6. Catalogue of Pavements and Work Units with Recycled Aggregates from Construction and Demolition Waste; UCO Press Editorial Universidad de Córdoba: Córdoba, Spain, 2017. 
7. Cartuxo, F.; De Brito, J.; Evangelista, L.; Jiménez, J.R.; Ledesma, E.F. Increased Durability of Concrete Made with Fine Recycled Concrete Aggregates Using Superplasticizers. Materials 2016, 9, 98. [CrossRef]

8. Guide to the Use of Recycled Aggregate and Recommendations for Its Purchase; Innovative Business Grouping for Efficient Construction (AEICE): Valladolid, Spain, 2018.

9. Ministry of Public Works. General Specifications for Roads and Bridges Works PG-3; 3th Part Explanations; Ministry of Public Works: Madrid, Spain, 2014; pp. 50-312.

10. Code on Structural Concrete (EHE-08); Ministry of Public Works: Madrid, Spanish, 2010.

11. Baghini, M.S.; Ismail, A.; Bin, K.; Mohamed, R. Evaluation of cement-treated mixtures with slow setting bitumen emulsion as base course material for road pavements. Constr. Build. Mater. 2015, 94, 323-336. [CrossRef]

12. Regulation (EU). n 305/2011 of the European Parliament and of the Council of 9 March 2011 laying down harmonised conditions for the marketing of construction products and repealing Council Directive 89/106/EEC. Off. J. Eur. Union 2011, 88, 5-43. Available online: https://tinyurl.com/y5k3fveo (accessed on 15 May 2020).

13. Agrela, F.; Barbudo, A.; Ramírez, A.; Ayuso, J.; Carvajal, M.D.; Jiménez, J.R. Construction of road sections using mixed recycled aggregates treated with cement in Malaga, Spain. Resour. Conserv. Recycl. 2012, 58, 98-106. [CrossRef]

14. Solutions for ecological paving and sustainable materials. In State of the Art Best Practices, Challenges and New and Emerging Technologies Technical Committee D.2 Road Pavements; World Road Association (PIARC): La Defense Cedex, France, 2019.

15. UNE-EN 13242:2003+A1. Aggregates for Unbound and Hydraulically Bound Materials for Use in Civil Engineering Work and Road Construction; AENOR: Madrid, Spain, 2008.

16. UNE-EN 933-1. Test for Geometrical Properties of Aggregates. Part 1: Determination of Particle Size Distribution. In Sieving Method; AENOR: Madrid, Spain, 2012.

17. UNE-EN 933-8:2012+A1:2015. Tests for geometrical properties of aggregates. In Part 8: Assessment of Fines; Sand Equivalent Test: Madrid, Spain, 2016.

18. UNE 103103. Determination of the Liquid Limit of a Soil; AENOR: Madrid, Spain, 2019.

19. UNE 103104. Determination of the Plastic Limit of a Soil; AENOR: Madrid, Spain, 2019.

20. UNE-EN 1097-2. Tests for mechanical and physical properties of aggregates. In Part 2: Methods for the Determination of Resistance to Fragmentation; AENOR: Madrid, Spain, 2010.

21. UNE 103 204. Organic Matter Content of a Soil by the Potassium Permanganate Method; AENOR: Madrid, Spain, 2019.

22. UNE 103205. Determination of Soluble Salts Content in Soils; AENOR: Madrid, Spain, 2019.

23. UNE-EN 1097-6. Tests for mechanical and physical properties of aggregates. In Part 6: Determination of Particle Density and Water Absorption; AENOR: Madrid, Spain, 2014.

24. UNE 103501. Geotechnics. Compaction Test. In Modified Proctor; AENOR: Madrid, Spain, 1994.

25. UNE 103502. Test Method for Determining in a Soil the California Bearing Ratio (CBR) Index; AENOR: Madrid, Spain, 1995.

26. Ministry of Public Works. Instruction for the Reception of Cements RC-16; Ministry of Public Works: Madrid, Spain, 2016.

(C) 2020 by the authors. Licensee MDPI, Basel, Switzerland. This article is an open access article distributed under the terms and conditions of the Creative Commons Attribution (CC BY) license (http://creativecommons.org/licenses/by/4.0/). 